NBER WORKING PAPER SERIES

\title{
HEALTH INSURANCE REFORM AND HMO PENETRATION IN THE SMALL GROUP MARKET
}

\author{
Thomas C. Buchmueller \\ Su Liu \\ Working Paper 11446 \\ http://www.nber.org/papers/w11446
}

\author{
NATIONAL BUREAU OF ECONOMIC RESEARCH \\ 1050 Massachusetts Avenue \\ Cambridge, MA 02138 \\ June 2005
}

Thomas C. Buchmueller: Paul Merage School of Business, University of California, Irvine, Irvine CA 926973125; phone 949-824-5247; fax: 949-725-2824; email: tcbuchmu@ uci.edu. The views expressed herein are those of the author(s) and do not necessarily reflect the views of the National Bureau of Economic Research.

(C2005 by Thomas C. Buchmueller and Su Liu. All rights reserved. Short sections of text, not to exceed two paragraphs, may be quoted without explicit permission provided that full credit, including $\odot$ notice, is given to the source. 
Health Insurance Reform and HMO Penetration in the Small Group Market

Thomas C. Buchmueller. Su Liu

NBER Working Paper No. 11446

June 2005

JEL No. I10, I18

\begin{abstract}
$\underline{\text { ABSTRACT }}$
We use data from several national employer surveys conducted between the late 1980s and the mid1990s to investigate the effect of state-level underwriting reforms on HMO penetration in the smallgroup health insurance market. We identify reform effects by exploiting cross-state variation in the timing and content of reform legislation and by using mid-sized and large employers, which were not affected by the legislation, as within-state control groups. While it is difficult to disentangle the effect of state reforms from other factors affecting HMO penetration in the small group markets, the results suggest a positive relationship between insurance market regulations and HMO penetration.
\end{abstract}

Thomas C. Buchmueller

Paul Merage School of Business

University of California Irvine

Irvine, CA 92697-3125

and NBER

tcbuchmu@uci.edu

Su Liu

Mathematica Policy Research, Inc

600 Maryland Ave SW

Washington, DC 20024

SLiu@Mathematica-Mpr.com 


\section{Introduction}

In the early to mid-1990s, nearly every state enacted legislation aimed at reforming the small group health insurance market. Motivated by concern about the problem of the medically uninsured, these laws targeted insurer marketing and underwriting practices that were seen to discriminate against "high risk" employer-sponsored groups. Several key components of these state-level reforms were incorporated in the federal legislation known as the Health Insurance Portability and Accountability Act (HIPAA), which was enacted in 1996 and went into effect the following year. More recently, several states have considered extending similar regulations to the individual health insurance market.

Assessing the economic effects of small group health insurance reforms of the 1990s is crucial both for understanding how health insurance markets work in general and for guiding future policies. A number of recent papers examine the effect of these statelevel reforms on health insurance coverage (Buchmueller and Jensen 1997; Sloan and Conover 1998; Jensen and Morrisey 1999; Hing and Jensen 1999; Zuckerman and Rajan 1999; Marquis and Long 2001/2002; Buchmueller and DiNardo 2002; Monheit and Schone 2004; Simon, forthcoming). These studies vary in the type of data used (individual vs. employer level), the time periods analyzed, the way state reforms are categorized, and econometric methodology. Despite these differences, most of these studies support a common conclusion that the state-level reforms had little effect on the number of people insured through the small group market.

This result, however, does not necessarily mean that the reforms had no impact at all (though this may be true in states that enacted minimal reforms). While the new laws were designed to proscribe insurer risk selection strategies, they did not eliminate the underlying incentives driving those strategies or the incentive for lower risk groups to seek 
out coverage at premiums reflecting their expected claims. As a result, the reforms may have affected the types of coverage sold and purchased in the small group market and the nature of competition between different types of insurers. In this paper we focus on one possible change: an increase in the percentage of small groups obtaining insurance coverage through a health maintenance organization (HMO).

Since HMO coverage is likely to be relatively more attractive to lower risk consumers, it represents a possible "self-selection" mechanism that may facilitate a separating equilibrium in a regulated market. As we discuss below, the reforms may also have "leveled the playing field" so as to increase the willingness of HMOs to participate in the small group market. So, there are strong theoretical reasons to expect an effect of these regulations on HMO penetration.

Our analysis uses data from several surveys of employers conducted between 1988 and 1995 to investigate the effect of small group reforms on the probability that small firms offered HMO coverage to their employees. Consistent with previous qualitative studies and quantitative work on a limited number of states, our results suggest that the new regulations increased HMO penetration in the small group market.

In the next section we summarize the main features of the small group reforms enacted by states. Then we discuss the relevant economic theory and review previous studies that touch on this question. In the fifth section we describe our data and our empirical approach and in the sixth section we present our econometric results. The concluding section summarizes the analysis, discusses developments in the market in the years since our analysis period, and identifies possible directions for future research. 


\section{The Small Group Reform Movement}

Most state-level small group reforms applied to groups of 50 or fewer employees and had three main components. Table 1 summarizes how these components varied across states as of 1995, the final year of our analysis. In general, states that enacted regulations that were strong in one dimension tended to enact strong rules in others, and vice versa. The table is arranged to provide a sense of these correlations which are an important factor determining how we categorize states in our empirical analysis.

The first reform component is rules limiting the ability of insurers to deny coverage to certain groups. The most basic regulations mandate the "guaranteed renewal" of insurance, which means that once a carrier agrees to sell insurance to a group it cannot later drop the group for reasons other than non-payment of premiums, fraud or other malfeasance. As shown in Table 1, as of 1995, 7 states had enacted legislation requiring only guaranteed renewal. For several reasons, the impact of these laws is likely to have been minimal. First, they do nothing for groups that were unable to purchase insurance in the first place. Second, even in the absence of a mandate it is not unusual for insurers to sell insurance on a guaranteed renewal basis. ${ }^{1}$ Third, unless the law also limits the amount by which premiums can increase from one year to the next, it is possible for insurers to use large premium increases to force undesirable groups to voluntarily drop coverage. As a result, it is not clear these laws should have significantly altered the behavior of many insurers or represented new protections for employer-sponsored groups.

"Guaranteed issue” laws go further by prohibiting insurers from denying coverage to any group that is willing to pay the premium. By 1995, 37 states had enacted some type

\footnotetext{
${ }^{1}$ Underwriting practices aimed at cream-skimming are much more prevalent in the individual health insurance market. Yet, according to Pauly and Percy (2000) prior to recent regulations 80 percent or more of individual health insurance policies contained guaranteed renewal provisions.
} 
of guaranteed issue regulation. Among this group, a distinction can be drawn between 23 states requiring the guaranteed issue of only a limited number of plans (typically two) and 14 states where the guaranteed issue rule applies to all plans sold in the small group market. $^{2}$

A second reform component is rating rules which specify which subscriber characteristics can and cannot be used to set premiums. The most restrictive is pure community rating, which requires carriers to charge the same premium to all groups purchasing a particular product, regardless of age, gender, health status or other variables that predict medical claims. Only one state-New York-adopted pure community rating. ${ }^{3}$ Next most restrictive are rules that allow premiums to vary with age, and in some cases other factors, but not subscriber health status. Laws that allow health status to be used in setting premiums commonly specify "rate bands” that limit the extent to which actual premiums can deviate from the "standard rate" defined for a given product. Since using age as a factor alone can generate up to a 5:1 spread in premiums, the combinations of age rating and rate bands can result in considerable premium differences across groups. ${ }^{4}$

The third main reform component limits insurers’ ability to exclude coverage for pre-existing medical conditions. The most common version allows conditions present 6 months prior to when an individual enrolls in a plan to be excluded for a maximum of 12 months after enrollment. Most state laws also included "portability” provisions that exempt insured individuals switching among health plans from these exclusions.

\footnotetext{
${ }^{2}$ The HIPAA legislation, which went into effect in 1997, requires the guaranteed issue of all plans sold in the small group market.

${ }^{3}$ New York required pure community rating in both the small group and individual markets. New Jersey also required community rating in the individual market but allowed insurers to vary small group rates on the basis of employee age, gender, and business location.

${ }^{4}$ For example, according to Ohio's law small group premiums must fall within a band of plus or minus 35 percent of a standard rate. This allows a difference of over 100 percent $(1.35 / 0.65)$ between the highest and lowest risk groups (Hall 2001/2002).
} 


\section{Theoretical and Institutional Background}

There are several reasons why these new regulations might have increased both the demand for and supply of HMO coverage in the small group market. Rothschild and Stiglitz's (1976) classic article on the economics of information in insurance markets is a useful starting point for considering these potential effects. In that model, when insurers have full information about consumer risk characteristics, all risk-averse consumers are offered and purchase full insurance at actuarially fair prices. This outcome is not possible when consumers have private information about their risk status. Instead, insurers may offer different policies that induce consumers to reveal their true risk type by the policies they select. In the resulting "separating” equilibrium, the market will be segmented with low risk consumers purchasing a lesser quantity of insurance than high-risk consumers.

Within this framework, imposing restrictions on insurer underwriting practices is analogous to moving from a situation of full information to one in which insurers have an information deficit. That is, even if they can observe consumer characteristics like the presence of health conditions or, in extreme cases age, they cannot use this information to determine whether or not to offer coverage or to set premiums. To the extent that these new constraints bind, the forced pooling of lower and higher risks will lead to higher premiums for low risks than would occur in an unregulated market. As in the RothschildStiglitz model, this gives them an incentive to seek out less expensive insurance policies that are relatively less attractive to high risks.

In a market with only indemnity insurance, self-selection may be based on plan cost-sharing. Insurance carriers may offer plans with different deductibles and coinsurance 
rates, hoping to attract low risk consumers to less comprehensive but less costly plans. ${ }^{5}$ In contemporary US health care markets, HMOs represent a potentially important selfselection mechanism (Feldman and Dowd 1994, 2000; Pauly and Nicholson 1999). HMO coverage can be seen as a lower quantity of insurance because of the restrictions placed on which providers patients can see and under what circumstances they can see them-i.e., limited provider panels, the use of gatekeepers and limits on referrals to specialists. ${ }^{6}$

Because these restrictions are likely to be viewed less negatively by low risk consumers than by high risks, market reforms that significantly alter insurer underwriting practices are likely to make HMO coverage more attractive to low risks, thereby increasing the market share of HMOs. ${ }^{7}$

This demand-side effect may be magnified by pre-existing differences in underwriting and marketing practices among insurers. Historically, HMOs have been less likely than commercial indemnity insurers to deny coverage on the basis of risk or to vary premiums according to subscriber risk status (Gabel 1997; Hall 2000a). Since the new regulations proscribed the risk-selection techniques used by indemnity insurers, but did not affect the way HMOs may be able to obtain favorable selection (e.g., through benefit

\footnotetext{
${ }^{5}$ In theory, another way that insurers may induce risk-based sorting is by offering products that are differentiated by benefit design. For example, plans that did not cover maternity care could be offered to appeal to a certain class of low-risk consumers. State benefit mandates generally preclude the use of this type of strategy in the US. However, according to Vaithianathan (2004), this is how Australian insurers have responded to community rating regulations in that country.

${ }^{6}$ Baker (2000) presents empirical evidence that HMO enrollees feel they are subject to more constraints and restrictions than people enrolled in non-HMO plans.

${ }^{7}$ It is well known that as managed care has evolved the distinctions among different types of plans-e.g., HMOs, point-of-service (POS) plans and preferred provider organizations (PPOs) - have blurred. Therefore, for some research questions it is managed care penetration, rather HMO penetration that is the relevant conceptual variable. For this separating equilibrium argument, there is empirical evidence suggesting that the most relevant distinction is between HMOs and non-HMOs, rather than between managed and non-managed care. Several studies show that when HMOs and PPOs are offered side by side there tends to be adverse selection against the PPOs, but among HMOs there is no evidence of biased selection by type of HMO (Buchmueller 1997, 1998; Cutler and Reber 1998; Yegian et al. 2000).
} 
design and provider selection), they may have made the small group market more attractive for HMOs and less attractive to their indemnity competitors.

\section{Previous Empirical Literature}

Existing empirical evidence on the question of whether state level reforms increased HMO penetration in the small group market is limited to a few studies, most of which focus on a small number of states. While this literature suggests a positive relationship between the imposition of new regulations and an increase in HMO penetration in the small group market, most of the studies lack a clear counterfactual, making it difficult to disentangle the impact of the reforms from a more general trend toward managed care.

Several qualitative studies provide valuable detail on how reforms were implemented and how key market participants viewed their effects. Kirk (2000) describes how individual market reforms in Washington, Kentucky and Massachusetts led commercial indemnity insurers to exit, and HMOs to enter those markets. Hall (1998, 2000a) documents large increases in HMO penetration in New York’s small group and individual markets after guaranteed issue and community rating were imposed in 1993. In this work and case studies of other states (Hall 2000a, 2000/2001), he quotes a number of informed observers who attribute rising HMO penetration in the small group market to insurance reforms, though he notes that other factors may also have contributed to this trend.

Buchmueller and DiNardo (2002) also focused on New York, comparing outcomes there to outcomes in Pennsylvania and Connecticut. They found that HMO penetration grew more rapidly in New York's small group market as compared to either of the other 
states or New York’s large group market. Changes in the demographic composition of the HMO and indemnity segments of the New York market were consistent with the hypothesis that many younger, healthier consumers responded to reform-induced premium increases by switching from indemnity plans to less costly HMO coverage.

Buchmueller and Jensen (1997) used two employer surveys from 1993 and 1995 to investigate changes in California’s small group market after reforms were enacted there in 1993. The results indicate a 20-point increase in the percentage of small firms choosing HMO coverage. However, HMO penetration increased as much for firms with 50-99 employees (who were not covered by the law) as for firms with 3 to 49 employees (who were covered). If HMOs consider groups just above and below 50 members as a single market, this could reflect a spillover effect of the law. Alternatively, the trend in both segments may be due to other contemporaneous factors.

Studies by Morrisey and Jensen (1997) and Marquis and Long (2001/2002) have important similarities to our analysis. Morrisey and Jensen use a subset of the same data we use to examine the decision by small employers to offer managed care plans. They find a positive association between the presence of small group reforms and the probability of offering a managed care plan. The effect is not statistically significant in a regression using data from 1993 but is significant at the .10 level in a data using 1995 data. Marquis and Long (2001/2002) use data from two surveys conducted in 1994 and 1997 to compare employers in 9 states that enacted moderate to strong reforms with 12 other states that either had no reforms or minimal reforms. The percentage of small firms offering HMO coverage increased by 20.4 percentage points in the reform states compared to an increase of 16 percentage points for small firms in the comparison states. However, this difference likely understates the impact of the reforms as the first of the two surveys was conducted 
after the legislation went into effect in 7 of the 9 reform states. In fact, in those 7 states where there was little or no change in regulations between 1994 and 1997, the growth in HMO penetration was only slightly higher than in the control states (19 percentage points). In contrast, HMO penetration grew 29 percentage points in the two states where the first survey predates the reforms.

An important difference between our study and the paper by Morrisey and Jensen is that our model includes state fixed effects that control for underlying differences between states that did and didn't enact reforms. Another is that instead of a single dummy variable for any small group reform, we distinguish between stronger and weaker reform legislation. The main difference between our study and Marquis and Long is that our data spans an earlier period, during which there was greater legislative activity. We now turn to our data and our econometric approach.

\section{Data and Econometric Specification}

The main source of data for our analysis is six surveys of employers conducted every year from 1988 to 1991 and in 1993 and 1995. The 1988-91 surveys were sponsored by the Health Insurance Association of America (HIAA) and the 1993 and 1995 surveys were done by KPMG/Peat Marwick, with sponsorship from the Robert Wood Johnson and Kaiser Family Foundations. All the surveys were administered by telephone to a sample of US employers drawn from Dun and Bradstreet’s nationwide list of firms. Our complete sample consists of 11,760 firms that have at least three employees and that offer some health benefits. ${ }^{8}$

\footnotetext{
${ }^{8}$ Our decision to model the demand for HMO coverage conditional on offering insurance is influenced by the fact that most studies find little or no effect of small group reforms on coverage.
} 
While the data set formed from these surveys is not without its weaknesses (the most important being its small size), it has three elements that are essential for our study: the type of coverage purchased (HMO vs. non-HMO), the state in which the firm is located, and the size of the firm. The first variable is the dependent variable in our analysis and the other two are necessary for identifying which firms were impacted by the statelevel reforms. ${ }^{9}$ Information on the content and timing of the various state reforms is from several sources, the most important being the detailed compendium of state laws prepared by Simon (2000). The employer survey data sets also provide information on the ZIP code in which each firm is located. With this information we can identify each firm's county and then merge the employer-level data with county-level determinants of HMO penetration from the Bureau of Health Profession's Area Resource File (ARF) and the Census Bureau’s County Business Patterns (CBP) data file.

The basic model we estimate is

$$
\begin{aligned}
& \begin{aligned}
H^{*}=X \beta+\gamma_{1} S M A L L+\gamma_{2} R E F O R M & +\gamma_{3} S M A L L X R E F O R M \\
& +\delta_{1} \text { STATE }+\delta_{2} Y E A R+\varepsilon
\end{aligned} \\
& H=1\left[H^{*>0}\right]
\end{aligned}
$$

where $H^{*}$ is a firm's latent propensity to offer HMO coverage and $H$ is its observed dichotomous analog. ${ }^{10}$ The vector $X$ consists of firm and area characteristics, SMALL is an indicator variable equaling one for firms with 50 or fewer employees (which is the most

\footnotetext{
${ }^{9}$ Most studies on the effects of the state-level reforms on insurance coverage use data from the Current Population Survey (CPS). The CPS is not a possibility for our analysis as there is no information on the type of insurance an individual holds. Similarly, other household surveys, such as the Survey of Income and Program Participation, the National Health Interview Survey, the National Medical Expenditure Survey and the Medical Expenditure Panel Survey lack one or more of the essential data elements.

${ }^{10}$ In principle, an alternative dependent variable would be the percentage of employees choosing HMO coverage. Unfortunately, we do not have a good, consistent measure of this outcome across the different surveys. For small firms, the two variables should be highly correlated, since during this period most small firms offered only one plan.
} 
common definition of the small group market used in reform legislation), and REFORM equals one if small group reform legislation was in effect in the particular state and year. We include a full set of state and year dummies to account for the fact that there is considerable variation across states in the prevalence of managed care and that managed care penetration was increasing over this period.

We interact the reform variable with the small firm dummy to account for the targeted nature of the reforms. The change in a small firm's propensity to offer an HMO after the enactment of small group reforms is given by $\gamma_{2}+\gamma_{3}$ and the corresponding change for larger firms is given by $\gamma_{2}$ alone. However, since the reforms should have had no direct effect on larger firms, $\gamma_{2}$ is best interpreted as representing the effect of other factors that were incidentally correlated with the timing of the reform legislation, making $\gamma_{3}$ a more precise estimate of the legislation's impact. ${ }^{11}$ We estimate robust standard errors to account for potential correlation of errors within state/year/firm size cells.

Summary statistics for the variables in our model are presented in Table 2.

Because of the way we use larger firms as in-state controls, we report separate statistics for firms with 50 or fewer employees and those with more than 50 . The most important firm characteristic available from the employer surveys is the number of employees. Not only is this variable essential for identifying firms that are subject to small group regulations, but firm size has an independent effect on HMO offers. In their early history, HMOs

\footnotetext{
${ }^{11}$ According to the theoretical arguments made above, the shift to HMOs should have been greatest for lower risk firms who benefited the most from risk-rating and therefore saw their premiums increase when tighter rating rules were enforced. Therefore, a stronger test of our hypothesis concerning the effect of small group reforms would be to add an additional interaction with some measure of risk. Unfortunately, this is not possible in these data. The information on employee demographics is limited and not consistent across years. Moreover, a convincing test of this type requires measures of risk factors that insurers could use in underwriting before the reforms, but not after. Age works as such a variable in the case of pure community rating, but not in most reform states where even after reforms age-rating was allowed. See Buchmueller (2004) for an extended discussion of this issue.
} 
marketed mainly to large employers. Even as HMOs have extended into other markets, a strong positive relationship between firm size and HMO coverage remains (Dranove et al. 1998). To account for possible spillover effects of firm size, we also include the percentage of establishments in the county with 100 or more employees. A similar measure has been used in previous studies as an instrument for market-level HMO penetration (see, e.g., Baker 1997).

Since it is difficult to establish provider networks in sparsely populated areas, we control for the percentage of the county’s population living in urban areas. The expectation is that this variable will be positively related to HMO offers. Other county level variables are the unemployment rate, median household income, the percentage of the county's population that is non-white, and the percent of adults with a college degree. We include these variables to account for within-state differences in consumer preferences, though there are not strong hypotheses concerning their effects.

A key issue in estimating this model is determining how to categorize the reforms enacted by different states. There was enough heterogeneity in the approaches taken by different states that a simple dichotomy between states with and without any reforms is not meaningful. At the same time, because the different small group reform components were typically enacted as a package (either all at once, or over a short period of time), it is neither meaningful nor practical to estimate the independent effect of each individual component. Therefore, like several previous researchers (Zuckerman and Rajan 1999; Marquis and Long 2001/2002; Monheit and Schone 2004; Simon forthcoming) we group states into a small number of categories based on the strength of their reforms.

Rules pertaining to guaranteed issue and renewal are important reform components for categorizing states. As noted, the weakest version of these laws requires only the 
guaranteed renewal of existing contracts. For reasons discussed above, these laws are unlikely to place significant constraints on the behavior of insurers. In addition, the reforms in states requiring guaranteed renewal but not guaranteed issue tended to be weaker in other dimensions, such as the limits placed on the dispersion of premiums and the treatment of pre-existing conditions. States with guaranteed renewal only were also more likely to use a narrower range of firm sizes to define the small group market. For these reasons, we group these states with the five states that enacted no reforms. ${ }^{12}$

Our preferred definition of reform states is limited to those that enacted some type of guaranteed issue law. As shown in Table 1, broader guaranteed issue laws are also positively correlated with stricter rating rules. While there are a number of different ways that rating regulations can be specified, the most important factor determining the "tightness" of the rules is whether or not insurers can use subscriber health status as a factor in setting premiums (Curtis et al. 1999). During the period of our analysis, twelve of the fourteen states requiring the guaranteed issue of all plans prohibited the use of health status in setting premiums; all but one states with partial guaranteed issue rules allowed insurers to adjust premiums to account for health. There was relatively little variation among states with any type of guaranteed issue with respect to rules on pre-existing conditions and portability. Thus, even if one believed that such rules affect the structure of the small group market, it is not possible empirically to identify their effect.

We estimate models that combine all guaranteed issue states into a single reform category, as well as models that distinguish between states mandating the guaranteed issue of all vs. some plans. To test the sensitivity of our results, we also estimate models that

\footnotetext{
12 This is consistent with the approach taken by Marquis and Long (20001/2002). The distinction between states requiring only guaranteed renewal and those with guaranteed issue mandates is the key factor determining the two reform categories_-partial and full_used by Simon (forthcoming).
} 
define reform states as those placing "tight” restrictions on the distribution of premiums. Following previous studies, we define tight rating rules as those that prohibit or significantly limit the use of health status in setting premiums. We identify such states using information provided by Simon (2000) and researchers at the Institute for Health Policy Solutions.

Several potential problems with this modeling strategy should be noted. First, however we categorize the reforms we are left with somewhat heterogeneous groupings. For example, earlier work (Buchmueller and DiNardo 2002) compared three states that represent different points on the reform continuum: New York, which enacted the strongest reforms in the country, Connecticut, which like New York required the guaranteed issue of all plans, but allowed significantly more variation in premiums, and Pennsylvania, which enacted no reforms. In our analysis New York and Connecticut are grouped together. Even among states with similar laws, there is heterogeneity in factors affecting the structure of the insurance market and the potential for HMO growth. For example, some of the most stringent reforms were enacted by Vermont and Maine, states that are sparsely populated and therefore not natural environments for HMOs to operate. As a result, regulations that would lead to an increase in HMO penetration in other markets might not have the same effect there. This within-group heterogeneity should cause our estimates to underestimate the effect of small group reforms on HMO penetration.

Other problems relate the use of firm size to define treatment and comparison groups of firms. First, the definition of small firms used in the legislation may not correspond precisely to the way insurers define market boundaries. A second source of measurement error is the fact that not all employees within a firm are offered or accept insurance coverage. Consequently, some firms with more than 50 employees will be 
groups of fewer than 50 for the purpose of purchasing insurance. The resulting ambiguity in the assignment of firms to the treatment and control groups will also cause the interaction term to understate the effect of the reforms. There is less ambiguity concerning the assignment of firms with, say, 100 or more employees. However, larger firms may not represent a suitable comparison group for those affected by small group legislation. If other factors caused HMO penetration to grow faster (slower) in the small group market than among larger firms, estimated reform effects based on the interaction term will be overstated (understated). We return to these issues below.

\section{Results}

Logit results are presented in Table 3. The results in column (1) are for a model with single reform category consisting of all states with any type of guaranteed issue. In column (2) we distinguish between the two types of guaranteed issue states, and in column (3) we define reform states according to whether or not they allow premiums to vary according to subscriber health status. All models include a full set of state and year fixed effects, which are not reported for reasons of space.

Before turning to our main results, we will briefly summarize the results for the control variables. In the specifications reported in the table, firm size enters quadratically along with a dummy variable for firms with fewer than 50 employees. As expected, we find a strong positive relationship between firm size and HMO offers. ${ }^{13}$ The coefficient on the percentage of establishments in the county with more than 100 employees is also positive and statistically significant. Another expected result is that HMO coverage is

\footnotetext{
${ }^{13}$ We also estimate models using a set of dummy variables for different firm size categories, which also imply a strong positive effect of firm size. The estimated effect of the reform laws is robust to alternative approaches to parameterizing the firm size effect.
} 
more prevalent in more urban areas. As noted, we did not have prior expectations concerning four county-level controls: median household income, the unemployment rate, the percent of the population that is non-white and the percent with at least a college degree. The coefficients on the first two of these variables are negative and the coefficients on the last two are positive. This pattern is similar to results reported by Dranove et al (1998). The result for the college degree variable is similar to Baker's (1997) finding that HMO penetration is higher in areas with a greater proportion of whitecollar workers.

Turning to our main results, all three models reported in Table 3 indicate that statelevel health insurance reforms contributed to an increase in HMO penetration in the small group market. In column (1) the coefficient on the interaction between the reform variable and the indicator for small firms is positive and significant at the .01 level (coefficient $=$ 0.641, t-statistic $=3.12$ ). The coefficient on the reform dummy alone, which represents the "effect” of small group reform legislation on larger firms that were not subject to the regulations, is essentially zero (coefficient $=-0.019$, absolute t-statistic $=0.19$ ). This result provides confidence that our estimate of effect of small group reforms is not driven by unobserved factors relating to which states enacted stronger reforms or when the reforms went into effect.

The results in column (2) indicate a slightly stronger effect of laws that require all plans to be offered on a guaranteed issue basis compared to laws requiring the guaranteed issue of some plans. However, the coefficients for the two categories are not significantly different from each other. When we define reform states according to rules on how premiums can be set (column 3), the results are quite similar to those using a definition 
based on guaranteed issue. This similarity is not surprising given the correlation of reform components discussed above.

With a logit model, the coefficient estimates provide little insight on the magnitude of effects, particularly in cases where the effects of interest are driven by interaction terms (Ai and Norton 2003). Therefore, in Table 4 we present simulation results based on the regression specifications reported in Table 3. For each observation in the sample, we predict the probability of offering coverage in the absence and presence of reforms, holding constant all firm and market characteristics and setting the year equal to $1995 .^{14}$ We then calculate the effect of the reforms based on the sample means for these predictions. We derive bootstrap standard errors for these predictions by randomly drawing 1000 replications from the estimated distribution of parameters (Efron and Tibshirani 1993).

The first panel reports results from the specification using a single reform variable (column 1 of Table 3). The second and third panels correspond to the other two specifications reported in Table 3. The simulations based on the model with the single reform category indicate that 17.3 percent of small employers would have offered an HMO to their employees in the absence of small group reform regulations. When strong small group reforms are in effect, the rate of HMO offers in the small group market rises to 29 percent, an increase of just under 12 percentage points. This is a 68 percent effect relative to the baseline rate. The results in the second panel show a slightly smaller effect for laws mandating the guaranteed issue of some plans (9.6 percentage points) and a slightly larger effect for laws requiring the guaranteed issue of all plans (13.2 percentage points). Using rating rules to define states with strong reforms yields an effect of 12 percentage points.

\footnotetext{
${ }^{14}$ We set the year equal to 1995 for ease of interpretation. The choice of year has virtually no effect on the magnitude of the reform effect.
} 
As suggested by the coefficient estimates, the percentage of larger firms that offer HMO coverage to their employees is essentially uncorrelated with the presence of underwriting regulations in the small group market. It declines slightly in the first two panels and increases slightly in the third, though in all three cases the change is not significantly different from zero. Subtracting the change for large firms from the change for smaller firms produces a “difference-in-difference-in-differences” type estimator. Since the effect for large firms is so small, doing so does not have a material impact on our estimate of the effect of the reforms.

To test the sensitivity of our results, we estimated the model on several different samples and using different firm size categories. Selected results are reported in Table 5. The figures in each row represent the estimated effect of small group reforms on the HMO offer rate using the same simulation methodology as in Table 4. Because the results are so similar for the different reform variables, we report only the results for the specification with the single guaranteed issue variable. For ease of comparison, we repeat the results from the full sample in the first row of the table.

As noted, there are several concerns about the use of firm size to identify reform effects. One is that using 50 employees as the cut-off point between small firms that should have been most affected by the reforms and larger firms that should not have been is essentially arbitrary. The figures in the second and third rows of Table 5 show that the results are fairly insensitive to the firm size cut-off point. When we define small firms as those with fewer than 40 employees, guaranteed issue is estimated to increase the percentage of small firms offering an HMO by 10.5 percentage points. When we use a cutoff of 60 employees, we obtain an estimated effect of 10.7 percentage points. In both cases 
the change for small firms is statistically significant, while the change for larger firms is small and insignificant.

A second concern related to firm size is that very large firms may not be an appropriate comparison group for firms that were the target of the small group reforms. Therefore we also estimate the model on a subsample that excludes firms with more than 250 employees. Using this restricted sample, small group reforms are estimated to increase the HMO offer rate among firms with 50 or fewer employees to 28.2 percent from 21.6 percent. While this is a smaller effect than implied by our full sample results, the difference is still statistically significant at the .01 level. The model indicates a slight (and statistically insignificant) decline in HMO penetration for firms with 51 to 250 employees, to just less than 33 percent from almost 39 percent. As a result, subtracting the reform/non-reform difference for large firms yields an estimated reform effect of 12.6 percentage points, which is comparable to the effect for the full sample.

The final specification check is motivated by the fact that the potential for HMO penetration varies significantly between urban and rural areas. To account for this, we also estimated the models on a subsample of firms in counties where at least half the population is classified as living in an urban area. These results are reported in the last row of Table 5. Dropping observations from largely rural counties increases both the baseline and postreform HMO penetration rates for both firm size categories, leaving the estimated effect of the reforms unchanged.

\section{Summary and Conclusions}

In the early to mid-1990s, nearly every state enacted some type of small group health insurance market reforms, which restricted insurer business practices that were seen 
to discriminate against high-risk groups. Evidence from a number of studies suggests that these laws neither led to a significant increase in health insurance coverage as reform advocates had hoped, nor caused coverage to fall as a result of market-wide adverse selection death spirals as a number of reform opponents have claimed. This is not to say, however, that the state-level reforms had no impact at all. The results of this paper corroborate the findings of earlier research focusing on a limited number of states indicating that the introduction of underwriting and marketing regulations appear to have affected the structure of the small group insurance market, contributing to an increase in HMO penetration.

For several reasons, we view our results as suggestive of the relationship between regulations and insurance market outcomes, rather than as a definitive estimate of a particular policy. First, our results represent an average effect for a set of states that vary considerably both with respect to the content of their laws and the underlying features of their health insurance markets. While these details cannot easily be incorporated in an econometric analysis, they are important for gaining a full understanding of the effects of health insurance market regulations. To give one example, Vermont's reform legislation allowed HMOs less rating flexibility than commercial indemnity carriers (Hall 2000b). This rule, combined with the low population density in the state helps to explain why HMO penetration has not increased as much in Vermont as it has in other states that enacted less stringent reforms. This type of cross-state variation points to the value of detailed state-specific analyses. We view this study as a complement, rather than a substitute for such research.

Second, there is a limit to how precisely "treatment” and “control” can be defined according to firm size. Even where reforms are in place, there may not be major 
differences in the treatment of firms with just fewer or just more than 50 employees. Much larger firms are easier to classify, but may not represent an appropriate comparison group for very small firms. Our results are not very sensitive to the cut-off point chosen, but are slightly sensitive to the inclusion or exclusion of very large firms.

It is also important to note that the shift toward increased HMO enrollment is but one of several ways that insurers and purchasers may have responded to new regulations in the small group market. Indemnity carriers that remained in reformed markets may have increased deductibles and coinsurance rates as a means of attracting and retaining low risk consumers. In addition, there is some evidence that reforms in certain states increased the prevalence of purchasing arrangements that are exempt from state insurance regulations, such as plans sponsored by professional and trade associations (Hall 2000b). It is not possible with our data to investigate the prevalence of these other outcomes, though such an inquiry is a promising direction for future research.

This final caveat is important in light of more recent market developments. It has been a decade since the last state enacted small group reform and the market has seen considerable changes. HMO enrollment peaked in the late 1990s and then declined during a periods of “managed care backlash.” Pauly and Nicholson (1999) provide an explanation for these developments that is based on the Rothschild-Stiglitz model and is consistent with our interpretation of our results. They note that while HMOs had historically attracted a disproportionately low-risk mix of enrollees, by the 1990s, the difference in premiums between HMOs and less restrictive plans became so large that many higher risk consumers began switching to HMOs. These new HMO members chafed at the constraints imposed by their new plans and their complaints led plans to manage care less tightly. This, combined with the fact that HMOs were no longer enrolling just a healthy minority 
of consumers, caused the premium differential between HMOs and PPOs to diminish, leading to some reverse migration from HMOs to PPOs. In the context of the RothschildStiglitz model, this story suggests that the shift to managed care that we observe in response to small group reforms may have been a temporary phenomenon, rather than a stable separating equilibrium.

More recently, employers have looked for other ways to respond to high and rising health insurance premiums. There has been growth in enrollment in high deductible plans with a PPO design including, but not limited to, plans offered in conjunction with a taxpreferred health savings account. Anecdotal accounts suggest that these new plans are beginning to alter the distribution of risks in certain markets, with high deductible PPOs becoming the preferred plan of younger, healthier consumers, leaving consumers with greater health needs in HMOs (see, for example, Girion 2005). In other words, these recent developments can be viewed as attempts by insurers and low-risk consumers to find a new separating equilibrium. Whether the end result is a stable equilibrium remains to be seen. 


\section{Acknowledgement}

We thank John DiNardo, Kate Bundorf, Jennifer Schultz, Tony LoSasso and Todd Gilmer for helpful comments and suggestions. Thanks also to Kosali Simon, Rafe Forland and Rick Curtis for sharing data they collected on the content of state reform legislation. 


\section{References}

Ai, Chunrong and Edward C. Norton. 2003. "Interaction Terms in Logit and Probit Models.” Economics Letters, 80(1):123-129.

Baker, Laurence, "The Effect of HMOs on Fee-For-Service Health Care Expenditures: Evidence from Medicare,” Journal of Health Economics, August 1997, 16(4), 453481.

-------“What Does HMO Market Share Measure? Examining Provider Choice Restrictions,” in Alan Garber ed., Frontiers in Health Policy Research, Volume 3, Cambridge MA: MIT Press, 2000.

Buchmueller, Thomas C. "Managed Competition in California's Small Group Health Insurance Market,” Health Affairs, 1997, 16(2): 218-228.

-------- “Does a Fixed-Dollar Premium Contribution Lower Spending? Health Affairs, 1998, 17(6): 228-235.

and Gail A. Jensen, "Small Group Reform in a Competitive Managed Care Market: The Case of California, 1993 to 1995,” Inquiry, Fall 1997, 34: 249-263.

. and John DiNardo, "Did Community Rating Induce an Adverse Selection Death Spiral? Evidence From New York, Pennsylvania, and Connecticut,” American Economic Review, March 2002, 92(1):280-294.

-------- "What Can We Learn from the Research on Small-Group Health Insurance Reform,” in State Health Insurance Market Reform: Toward Inclusive and Sustainable Health Insurance Markets, A.C. Monheit and J.C. Cantor, eds. 2004, 67-81.

Curtis, Risk, Stephen Lewis, Kevin Haugh and Rafe Forland, "Health Insurance Reform in the Small-Group Market,” Health Affairs, May/June 1999, 18(3), 151-160.

Cutler, David and Sarah Reber, "Paying for Health Insurance: The Tradeoff Between Competition and Adverse Selection,” Quarterly Journal of Economics, 1998, 113(2): 433-466.

Dranove, David, Carol J. Simon and William D. White, “Determinants of Managed Care Penetration,” Journal of Health Economics, 1998, 17: 729-745.

Efron, Bradley and Robert J. Tibshirani, “An Introduction to the Bootstrap,” Chapman \& Hall. New York. 1993.

Feldman, Roger and Bryan Dowd, "Biased Selection: Fairness and Efficiency in Health Insurance Markets,” in Robert B. Helms, ed., American Health Policy, Washington, DC: AEI Press, 1994, chapter 4, 64-86. 
------“Risk Segmentation: Goal or Problem,” Journal of Health Economics, 2000, 19() 499-512.

Gabel, Jon, “Ten Ways HMOs Have Changed During the 1990s,” Health Affairs, 1997, 16(3), 134-145.

Girion, Lisa, "HMOs in Unstable Condition: Members Bolt to Other Plans," Los Angeles Times, April 9, 2005.

Hall, Mark, “An Evaluation of New York’s Health Insurance Market Reform Laws,” unpublished manuscript, Wake Forest University, February1998.

-------, “The Impact of Health Insurance Market Reforms on Market Competition,” American Journal of Managed Care, January 2000a, 6(1):685-721.

-------, “An Evaluation of Vermont’s Reform Law,” Journal of Health Politics, Policy and Law, February 2000b, 25(1), 101-131.

-------, “The Structure and Enforcement of Health Insurance Rating Reforms,” Inquiry, Winter 2000/2001, 37: 376-388.

Hing, Esther and Gail A. Jensen, "Health Insurance Portability and Accountability Act of 1996, Lessons from the States,” Medical Care, July 1999, 37(7), 692-705.

Kirk, Adele M. "Riding the Bull: Reform in Washington, Kentucky, and Massachusetts." Journal of Health Politics, Policy and Law, February 2000, 25(1): 133-173.

Marquis, M. Susan and Stephen H. Long, "Effects of 'Second Generation' Small Group Health Insurance Market Reforms 1993 to 1997," Inquiry, Winter 2001/2002, 38(4), 365-380.

Monheit, Alan C. and Barbara Steinberg Schone, "How has Small Group Market Reform Affected Employee Health Insurance Status?” Journal of Public Economics, 2004, 88(1-2): 237-254.

Morrisey, Michael A. and Gail A Jensen, "Switching to Managed Care in the Small Employer Market,” Inquiry, 1997, 34(3): 237-248.

Pauly, Mark V. and Sean Nicholson, “Adverse Consequences of Adverse Selection,” Journal of Health, Politics, Policy and Law, October 1999, 24(5): 921-930.

Pauly, Mark V. and Allison M. Percy, "Cost and Performance: A Comparison of the Individual and Group Health Insurance Markets," Journal of Health Politics, Policy and Law, February 2000, 25(1), 9-26.

Rothschild, Michael and Joseph Stiglitz, "Equilibrium in Competitive Insurance Markets: An Essay on the Economics of Imperfect Information," Quarterly Journal of Economics, November 1976, 90(4), 629-649. 
Simon, Kosali Ilayperuma, Adverse Selection in Health Insurance Markets? Evidence from state small-group health insurance reforms " Journal of Public Economics, forthcoming.

-------, "Legislative Summaries of State Small-Group Health Insurance Reform 19901999," Unpublished Manuscript, University of Maryland, March 2000.

Sloan, Frank A. and Christopher J. Conover, "Effects of State Reforms on Health Insurance Coverage of Adults,” Inquiry, Fall 1998, 35: 280-293.

Vaithianathan, Rhema, “A Critique of the Private Health Insurance Regulations,” The Australian Economic Review, 2004, 37(3): 257-70.

Yegian, Jill, Thomas C. Buchmueller, Mark Smith and Anne Monroe, "The Health Insurance Plan of California: The First Five Years,” Health Affairs, 2000, 19(5): 158-165.

Zuckerman, Stephen and Shruti Rajan, "An Alternative Approach to Measuring the Effects of Insurance Market Reforms,” Inquiry, Spring 1999, 36: 44-56. 
Table 1. A Summary of State Level Small Group Reforms as of 1995

\begin{tabular}{lccc} 
& \multicolumn{3}{c}{ Guaranteed Renewal(GR)/ Guaranteed Issue (GI) } \\
& GR Only & GI, Some Plans & GI, All Plans \\
\hline Number of States & 7 & 23 & 14 \\
Rating Rules & & & \\
$\quad$ Pure Community Rating & 0 & 0 & 1 \\
Health Prohibited as a Rating Factor & 0 & 0 & 9 \\
Limits on Exclusion of Pre-Existing Conditions & & \\
Any limit & 5 & 23 & 14 \\
6/6 & 1 & 2 & 4 \\
6/12 & 1 & 16 & 2 \\
12/12 & 3 & 5 & 3 \\
other & 0 & 0 & \\
\end{tabular}

Source: Simon (2000).

Notes: 6/12 means that conditions present up to 6 months prior to enrollment can be excluded from coverage for a maximum of 12 months. The states falling in each category (and the year that their law was enacted) are as follows. GR Only: Arkansas (1992), Georgia (1991), Indiana (1992), Illinois (1994), Louisiana (1991), New Mexico (1991), West Virginia (1991). GI-Some: Alaska (1993), Arizona (1994), Colorado (1995), Delaware (1992), Idaho (1993), Iowa (1992), Kansas (1992) Mississippi (1995), Missouri (1994), Montana (1995), Nebraska (1994), North Carolina (1991), North Dakota (1993), Ohio (1993), Oklahoma (1994), Oregon (1991), Rhode Island (1992), South Carolina (1995), South Dakota (1995), Tennessee (1993), Virginia (1993), Wisconsin (1991), Wyoming (1993). GI-All: California (1993), Connecticut (1991), Florida (1994), Kentucky (1995), Maine (1990), Maryland (1994), Massachusetts (1991), Minnesota (1993), New Hampshire (1995), New Jersey (1994), New York (1993), Texas (1994), Washington (1993), Vermont (1992). 
Table 2. Summary Statistics, Small vs. Large Firms

\begin{tabular}{|c|c|c|c|c|}
\hline & \multicolumn{2}{|c|}{$\begin{array}{c}\text { Small Firms } \\
\text { (3-50 employees) }\end{array}$} & \multicolumn{2}{|c|}{$\begin{array}{c}\text { Large Firms } \\
\text { (50+ employees) }\end{array}$} \\
\hline & Mean & $\begin{array}{l}\text { Standard } \\
\text { Deviation }\end{array}$ & Mean & $\begin{array}{l}\text { Standard } \\
\text { Deviation }\end{array}$ \\
\hline \multicolumn{5}{|l|}{ Dependent Variable } \\
\hline$\overline{\text { Firm offers an HMO }}$ & 0.161 & 0.367 & 0.466 & 0.499 \\
\hline \multicolumn{5}{|l|}{ Reform Variables } \\
\hline$\overline{\text { Guaranteed issue, some plans }}$ & 0.106 & 0.308 & 0.086 & 0.280 \\
\hline Guaranteed issue, all plans & 0.118 & 0.323 & 0.096 & 0.294 \\
\hline Tight rating rules & 0.101 & 0.301 & 0.081 & 0.273 \\
\hline \multicolumn{5}{|l|}{ Control Variables } \\
\hline$\overline{\text { Number of employees }}$ & 20.68 & 14.58 & 4629.6 & 22322.7 \\
\hline County unemployment rate & 6.10 & 2.25 & 5.91 & 2.08 \\
\hline County median income $(\$ 1000)$ & 19.66 & 5.58 & 19.48 & 5.56 \\
\hline \multicolumn{5}{|l|}{$\%$ of county establishments with $>100$} \\
\hline employees & 2.201 & 0.708 & 2.359 & 0.671 \\
\hline$\%$ of county population in urban area & 75.54 & 26.09 & 79.28 & 23.27 \\
\hline$\%$ of county population nonwhite & 18.12 & 14.71 & 19.78 & 14.71 \\
\hline$\%$ of county population with college degree & 13.75 & 5.68 & 14.01 & 5.44 \\
\hline Year $=1988$ & 0.086 & 0.280 & 0.103 & 0.304 \\
\hline Year $=1989$ & 0.163 & 0.369 & 0.170 & 0.376 \\
\hline Year $=1990$ & 0.168 & 0.374 & 0.246 & 0.430 \\
\hline Year = 1991 & 0.220 & 0.414 & 0.206 & 0.404 \\
\hline Year $=1993$ & 0.197 & 0.398 & 0.124 & 0.329 \\
\hline Year $=1995$ & 0.166 & 0.372 & 0.152 & 0.359 \\
\hline SAMPLE SIZE & \multicolumn{2}{|c|}{2246} & \multicolumn{2}{|c|}{9514} \\
\hline
\end{tabular}


Table 3. Logit Results: The Effect of Small Group Reform on HMO Offers

\begin{tabular}{|c|c|c|c|}
\hline & (1) & $(2)$ & (3) \\
\hline Small firm (3 to 50 employees) & $\begin{array}{l}-1.710^{*} \\
(0.102)\end{array}$ & $\begin{array}{l}-1.707^{*} \\
(0.102)\end{array}$ & $\begin{array}{l}-1.629 * \\
(0.095)\end{array}$ \\
\hline Guaranteed issue & $\begin{array}{l}-0.019 \\
(0.098)\end{array}$ & ----- & ------ \\
\hline Guaranteed issue $\mathrm{x}$ small firm & $\begin{array}{c}0.641^{*} \\
(0.206)\end{array}$ & ------ & ------ \\
\hline Guaranteed issue-some plans & ------ & $\begin{array}{l}-0.088 \\
(0.115)\end{array}$ & ------ \\
\hline Guaranteed issue-some plans $x$ small firm & ------ & $\begin{array}{c}0.585^{*} \\
(0.246)\end{array}$ & ------ \\
\hline Guaranteed issue-all plans & ------ & $\begin{array}{c}0.048 \\
(0.117)\end{array}$ & ------ \\
\hline Guaranteed issue-all plans $x$ small firm & ------ & $\begin{array}{c}0.657^{*} \\
(0.266)\end{array}$ & ------ \\
\hline Tight rating rules & & & $\begin{array}{c}0.136 \\
(0.113)\end{array}$ \\
\hline Tight rating rules $\mathrm{x}$ small firm & & & $\begin{array}{c}0.561 \\
(0.278)\end{array}$ \\
\hline Number of employees & $\begin{array}{l}5.5 \times E-5^{*} \\
(8.9 \times E-6)\end{array}$ & $\begin{array}{c}5.5 \times E-5 \\
(8.9 \times E-6)\end{array}$ & $\begin{array}{l}5.5 \times E-5^{*} \\
(8.9 \times E-6)\end{array}$ \\
\hline (Number of Employees) $^{2}$ & $\begin{array}{l}-5.5 \times E-11^{*} \\
(8.6 \times E-12)\end{array}$ & $\begin{array}{l}-5.4 \times E-11 \\
(8.6 \times E-12)\end{array}$ & $\begin{array}{l}-5.4 \times E-11^{*} \\
(8.6 \times E-12)\end{array}$ \\
\hline County unemployment rate & $\begin{array}{l}-0.042^{*} \\
(0.017)\end{array}$ & $\begin{array}{l}-0.046^{*} \\
(0.018)\end{array}$ & $\begin{array}{l}-0.050^{*} \\
(0.019)\end{array}$ \\
\hline County median income & $\begin{array}{l}-0.031^{*} \\
(0.011)\end{array}$ & $\begin{array}{l}-0.031^{*} \\
(0.011)\end{array}$ & $\begin{array}{l}-0.030^{*} \\
(0.011)\end{array}$ \\
\hline$\%$ of county establishments with $>100$ employees & $\begin{array}{c}0.223^{*} \\
(0.060)\end{array}$ & $\begin{array}{c}0.222^{*} \\
(0.060)\end{array}$ & $\begin{array}{c}0.217^{*} \\
(0.060)\end{array}$ \\
\hline$\%$ of county population in urban area & $\begin{array}{c}0.016^{*} \\
(0.002)\end{array}$ & $\begin{array}{c}0.016^{*} \\
(0.002)\end{array}$ & $\begin{array}{c}0.016^{*} \\
(0.002)\end{array}$ \\
\hline$\%$ of county population nonwhite & $\begin{array}{c}0.005 \\
(0.003)\end{array}$ & $\begin{array}{c}0.005 \\
(0.003)\end{array}$ & $\begin{array}{c}0.005 \\
(0.003)\end{array}$ \\
\hline$\%$ of county population with college degree & $\begin{array}{c}0.038^{*} \\
(0.011) \\
\end{array}$ & $\begin{array}{c}0.037 * \\
(0.011) \\
\end{array}$ & $\begin{array}{c}0.037^{*} \\
(0.011) \\
\end{array}$ \\
\hline Log Likelihood & -6370.03 & -6369.27 & -6372.18 \\
\hline
\end{tabular}


Table 4. Simulation Results: The Effect of Small Group Reforms on HMO Offers

\begin{tabular}{|c|c|c|c|}
\hline & $\begin{array}{c}\text { (1) } \\
\text { Small Firms }\end{array}$ & $\begin{array}{c}(2) \\
\text { Large Firms }\end{array}$ & $\begin{array}{c}(3) \\
\text { Difference } \\
(1-2) \\
\end{array}$ \\
\hline $\begin{array}{l}\text { 1. Guaranteed Issue-1 Category } \\
\text { a. No Guaranteed Issue Law }\end{array}$ & $\begin{array}{c}0.173 \\
(0.016)\end{array}$ & $\begin{array}{c}0.528 \\
(0.018)\end{array}$ & \\
\hline b. Guaranteed Issue Law & $\begin{array}{c}0.291 \\
(0.031)\end{array}$ & $\begin{array}{c}0.524 \\
(0.015)\end{array}$ & \\
\hline Difference $(b-a)$ & $\begin{array}{c}0.118 \\
(0.015) \\
\end{array}$ & $\begin{array}{l}-0.008 \\
(0.003)\end{array}$ & $\begin{array}{c}0.126 \\
(0.018)\end{array}$ \\
\hline $\begin{array}{l}\text { 2. Guaranteed Issue-2 Categories } \\
\text { a. No Guaranteed Issue Law }\end{array}$ & $\begin{array}{c}0.173 \\
(0.016)\end{array}$ & $\begin{array}{c}0.524 \\
(0.018)\end{array}$ & \\
\hline b. Guaranteed Issue, Some Plans & $\begin{array}{c}0.269 \\
(0.035)\end{array}$ & $\begin{array}{c}0.506 \\
(0.018)\end{array}$ & \\
\hline Difference $(b-a)$ & $\begin{array}{c}0.096 \\
(0.019)\end{array}$ & $\begin{array}{l}-0.018 \\
(0.001)\end{array}$ & $\begin{array}{c}0.114 \\
(0.019)\end{array}$ \\
\hline c. Guaranteed Issue, All Plans & $\begin{array}{c}0.305 \\
(0.043)\end{array}$ & $\begin{array}{c}0.533 \\
(0.019)\end{array}$ & \\
\hline Difference $(c-a)$ & $\begin{array}{c}0.132 \\
(0.028)\end{array}$ & $\begin{array}{c}0.009 \\
(0.002)\end{array}$ & $\begin{array}{c}0.123 \\
(0.026)\end{array}$ \\
\hline
\end{tabular}

\section{Tight Rating Rules}

a. No Tight Rating Rules $\quad 0.178 \quad 0.518$

$(0.015) \quad(0.015)$

b. Tight Rating Rules $\quad 0.301 \quad 0.547$

$(0.045) \quad(0.02)$
Difference $(b-a)$
0.123
0.029
(0.006)
0.094
(0.03)
$(0.024)$

Notes: The number of observations is 11760. Small and large firms are defined as those with fewer and greater than 50 employees, respectively. Offer rates were simulated by setting the reform variables equal to zero and one for each observation and predicting the probability of offering an HMO. The year variable was set to 1995. The probabilities were then averaged over the full sample within each size category. Bootstrapped standard errors are in parentheses. 
Table 5. Alternative Estimates of the Effect of Small Group Reforms on HMO Offers

\section{Estimated Change in HMO Offer Rate for:}

1. Full sample

\begin{tabular}{cc} 
Small Firms & Large Firms \\
\hline 0.118 & -0.008 \\
$(0.015)$ & $(0.003)$ \\
& \\
0.105 & 0.008 \\
$(0.01)$ & $(0.002)$ \\
& \\
0.107 & -0.008 \\
$(0.011)$ & $(0.004)$ \\
& \\
0.066 & -0.06 \\
$(0.001)$ & $(0.005)$ \\
& \\
0.135 & 0.007 \\
$(0.007)$ & $(0.005)$
\end{tabular}

Notes: Reform effects are based on simulations described in the note to Table 4 . In all models, the reform variable is an indicator for the presence of a guaranteed issue requirement. Except were noted otherwise, small and large firms are defined as those with fewer and more than 50 employees, respectively. Bootstrapped standard errors are in parentheses. 